ORIGINAL ARTICLE

\title{
Maternal pre-pregnancy BMI, gestational weight gain and breastfeeding
}

\author{
H Castillo ${ }^{1}$, IS Santos ${ }^{2}$ and A Matijasevich ${ }^{3}$
}

\begin{abstract}
BACKGROUND/OBJECTIVES: The aims were to investigate the association of maternal pre-pregnancy body mass index (BMI) and gestational weight gain (GWG) with breastfeeding (BF) duration and BF pattern at 3 months of age.

SUBJECTS/METHODS: This was a prospective cohort study of 4231 children who were enrolled at birth and were followed-up at 3, 12,24 and 48 months of age to gather information on maternal and offspring characteristics including BF patterns and BF duration. Maternal pre-pregnancy BMI was categorized according to the WHO classification and GWG according to the 2009 Institute of Medicine recommendations. Cox's proportional hazards model was used to assess whether pre-pregnancy BMI and GWG were associated with BF and exclusive breastfeeding (EBF) duration. Predicted probabilities of BF patterns at 3 months were estimated by multinomial logistic regression.

RESULTS : Information on BF was available to 4011 infants. The total BF and EBF median durations were 7.0 months and 1.5 months, respectively. There were no differences in duration of any BF or EBF according to pre-pregnancy BMI or GWG categories. There was an increased predicted probability for weaning before the age of 3 months among infants from obese women, compared with those from mothers with normal pre-pregnancy BMI, with margins adjusted predictions of 0.36 ( $95 \%$ confidence interval $(\mathrm{Cl}) 0.31-0.41)$ and $0.23(95 \% \mathrm{Cl} 0.21-0.25)$, respectively.

CONCLUSIONS: Infants from pre-pregnancy overweight/obese mothers presented higher probability of early weaning compared with infants from normal-weight mothers. Obese/overweight pregnant women need supplementary guidance about BF benefits to infant health during prenatal and postnatal care.
\end{abstract}

European Journal of Clinical Nutrition (2016) 70, 431-436; doi:10.1038/ejcn.2015.232; published online 27 January 2016

\section{INTRODUCTION}

The obesity prevalence is increasing worldwide and particularly in high-income countries is an emergent problem in public health. ${ }^{1}$ This condition elevates the risk of several non-communicable diseases $^{2}$ and is considered as a major risk factor for women morbidity and mortality during the reproductive age. ${ }^{3}$ Epidemiologic studies suggest that maternal obesity can be considered as a risk factor to adverse breastfeeding (BF) outcomes. ${ }^{4,5}$ The association of maternal obesity and inappropriate BF can represent major risk to children health and development. ${ }^{6}$ It is not clear whether the timing of adiposity gain can differently impact BF outcomes. Although pre-pregnancy body mass index (BMI) and gestational weight gain (GWG) are strongly correlated, ${ }^{7}$ their independent effect over BF outcomes needs to be explored.

Nonetheless, information on maternal behavioral modifiable determinants of BF duration is lacking at the literature. ${ }^{8,9}$ Therefore, the aims of the present study were to investigate the association between maternal pre-pregnancy BMI and GWG on BF duration and on patterns of $\mathrm{BF}$ at 3 months of age among children from the 2004 Pelotas Birth Cohort (Brazil).

\section{MATERIALS AND METHODS}

During 2004, a birth cohort study was started in Pelotas, Southern Brazil. All births from residents in the urban area of the city were enrolled (4231 live births). Newborns were examined and mothers interviewed during their stay in the five hospitals of the city ( $99 \%$ of deliveries). Infants were visited at home for another examination at 3 months (95.7\%), 12 months (94.3\%), 24 months and 48 months $(92.0 \%)$ of age. ${ }^{10}$ The present study included only single births.
Maternal variables
Pre-pregnancy BMI was calculated as $\mathrm{kg} / \mathrm{m}^{2}$. Maternal weight at the beginning of pregnancy was extracted from prenatal card or when absent by self-report. Maternal height was measured in the first follow-up at 3 months post partum. ${ }^{10}$ Maternal pre-pregnancy BMI was categorized according to the WHO classification as underweight $\left(<18.5 \mathrm{~kg} / \mathrm{m}^{2}\right)$, normal weight $\left(18.5-24.9 \mathrm{~kg} / \mathrm{m}^{2}\right)$, overweight $\left(25.0-29.9 \mathrm{~kg} / \mathrm{m}^{2}\right)$ and obese $\left(\geqslant 30.0 \mathrm{~kg} / \mathrm{m}^{2}\right)$. ${ }^{11} \mathrm{GWG}$ in $\mathrm{kg}$ was calculated as the difference between pre- pregnancy weight and the last register of weight in the prenatal card at delivery. According to the Institute of Medicine (IOM), underweight women category should aim to gain $12.5-18.0 \mathrm{~kg}$ during pregnancy; those with normal BMI, 11.5-16.0 kg; the overweight, 7.0-11.5 kg; and the obese, 5.0- $9.0 \mathrm{~kg}^{9}$. Both preterm and post-term pregnancies were adjusted to recommended ranges, using the expected weekly weight gain. ${ }^{11,12}$ Maternal GWG categories were then defined as gaining above the recommended amount, gaining the recommended amount, or gaining below the recommended amount (excessive, sufficient and insufficient weight gain, respectively). ${ }^{12}$
Several maternal covariates obtained from the perinatal study were included as self-reported: maternal years of formal education (continuous); skin color and categorized as white, black, mulatto/brown, mixed or others; smoking (yes/no) and alcohol consumption (yes/no) during the pregnancy; history of diseases (arterial hypertension and diabetes mellitus) during the pregnancy. Variables measurement or extracted from prenatal card: family monthly income at birth (continuous variable); parity (primiparous/ 
multiparous); maternal age (continuous); and type of delivery (vaginal or caesarian section). ${ }^{10}$

\section{Children variables}

At the 3 month, 12 month and 24 month follow-ups, the frequency of exclusive breastfeeding (EBF) and any BF was evaluated by means of a personal interview with the mother. ${ }^{13}$ Children were considered as on EBF if they were given no other food or drink, not even water, except breast milk (including milk expressed or from a wet nurse) for 6 months of life, but allows the infant to receive oral rehydration salts, drops and syrups (vitamins, minerals and medicines). Predominant BF means that the infant's predominant source of nourishment has been breast milk (including milk expressed or from a wet nurse as the predominant source of nourishment). However, the infant may also have received liquids (water and water-based drinks, fruit juice), ritual fluids and oral rehydration salts, drops or syrups (vitamins, minerals and medicines). In partial BF if they received breast milk, herbal tea, fruit juice, and/or water, other milk and/or semisolids). ${ }^{14}$

Child anthropometric measurements, sex and gestational age were collected at birth. Gestational age was estimated using an algorithm proposed by the National Center for Health Statistics based on the last menstrual period. ${ }^{15}$ If the birth weight, length and head circumference were inconsistent with the normal curves for the gestational age calculated, or if the date of the last menstrual period was unknown, ${ }^{16}$ then gestational age was determined using the Dubowitz method, which was performed on almost all newborns. ${ }^{17}$

\section{Statistical analysis}

Statistical analyses were carried out using Stata version 12.0 (StataCorp, College Station, TX, USA). The median duration of any BF and EBF was calculated in months but to survival analyses the duration was converted in days. EBF survival was defined as the time interval between onset of EBF and the introduction of water, herbal teas or other types of milk or other foods. BF duration was defined as the time elapsed interval between onset of any $\mathrm{BF}$ and total interruption of $\mathrm{BF}$. Any $\mathrm{BF}$ and $\mathrm{EBF}$ survival were estimated by Cox regression. To test whether proportional hazard assumption was held, a test of interaction between independent variables and time was performed. The models assume that the hazard rate is constant over time. Statistically significant interaction between any BF duration and maternal smoking during pregnancy as well as between EFB duration and parity were found; so, subsequent analyses were stratified according to these variables.

To examine whether BF patterns at 3 months of age differed according to pre-pregnancy BMI and GWG adjusted to covariates the multinomial logistic regression was used. We used the marginsplot STATA command to plot the probabilities of BF patterns by maternal pre-pregnancy BMI and GWG categories. All analyses were adjusted for maternal age, mother's schooling, socio-economic level, mother's skin color, parity, smoking during pregnancy, alcohol consumption, history of diseases (arterial hypertension and diabetes mellitus), child sex, birth weight, gestational age at birth and type of delivery.

\section{RESULTS}

Information on offspring BF and maternal pre-pregnancy BMI was available for 3757 infants and on offspring BF and maternal GWG for 3723 infants. All variables except maternal age and child sex had significantly losses comparing with the original population. Mean values of maternal age, schooling, pre-pregnancy BMI and GWG were 26.1 years (s.d. 6.8), 8.5 years (s.d. 3.5), $24.2 \mathrm{~kg} / \mathrm{m}^{2}$ (s.d. 4.67) and $12.4 \mathrm{~kg}$ (s.d. 6.1), respectively. Table 1 summarizes the population characteristics. At birth, $20.4 \%$ of families were on the poorest quintile of monthly income, $61.7 \%$ mothers had white skin color, $39.7 \%$ were primiparous and $27.5 \%$ of them smoked during pregnancy. Less than $5 \%$ of the mothers $(4.9 \%)$ were underweight, $61.0 \%$ were in normal weight, $23.2 \%$ were overweight and $10.9 \%$ were obese. In accordance of IOM GWG classification: $30.4 \%$ gained insufficient, $36.0 \%$ sufficient and $33.6 \%$ excessive weight during pregnancy.
Table 1. Characteristics of participants in the original cohort and the percentage analyzed (2004 Pelotas Birth Cohort; Pelotas, Brazil)

\begin{tabular}{|c|c|c|c|}
\hline Co-variables & $\begin{array}{l}\text { Original } \\
\text { cohort } \\
\mathrm{N}(\%)\end{array}$ & $\begin{array}{c}\text { Available } \\
\text { information at } \\
3 \text { months of } \\
\text { age } \\
\mathrm{N}(\%)\end{array}$ & $\begin{array}{l}\text { Available } \\
\text { information } \\
\text { at } 12 \text { months } \\
\text { of age } \\
\mathrm{N}(\%)\end{array}$ \\
\hline $\begin{array}{l}\text { Total } \\
\text { Family monthly income } \\
\text { (quintiles) }\end{array}$ & 4147 & $\begin{array}{c}4011 \\
P=0.002\end{array}$ & $\begin{array}{c}3757 \\
P<0.001\end{array}$ \\
\hline 1 (poorest) & 846 (20.4) & $806(20.1)$ & 709 (18.9) \\
\hline 2 & $841(20.3)$ & $803(20.0)$ & 737 (19.6) \\
\hline 3 & 802 (19.3) & 782 (19.5) & 745 (19.8) \\
\hline 4 & 846 (20.4) & $829(20.7)$ & $795(21.2)$ \\
\hline 5 (wealthiest) & $812(19.6)$ & 791 (19.6) & $771(20.5)$ \\
\hline Schooling, years & & $P=0.006$ & $P<0.001$ \\
\hline Up to 4 & 639 (15.6) & $608(15.3)$ & 505 (13.6) \\
\hline $5-8$ & 1691 (41.2) & 1629 (41.0) & $1520(40.8)$ \\
\hline $9-11$ & $1362(33.2)$ & 1334 (33.6) & 1301 (34.9) \\
\hline$\geqslant 12$ & $414(10.1)$ & $402(10.1)$ & $394(10.6)$ \\
\hline Maternal skin color & & $P=0.05$ & $P<0.001$ \\
\hline White & $2528(61.7)$ & 2459 (62.0) & 2340 (62.9) \\
\hline Black & $675(16.5)$ & $648(16.3)$ & 584 (15.7) \\
\hline Mulatto/Brown /Others & 896 (21.9) & $858(21.6)$ & $796(21.4)$ \\
\hline Maternal age, years & & $P=0.59$ & $P=0.46$ \\
\hline$<20$ & $792(19.1)$ & $762(19.0)$ & $713(18.9)$ \\
\hline $20-35$ & 2919 (70.4) & $2825(70.5)$ & 2656 (70.6) \\
\hline$>35$ & $434(10.5)$ & $422(10.5)$ & $388(9.4)$ \\
\hline Primiparity & & $P=0.87$ & $P<0.001$ \\
\hline Yes & 1644 (39.7) & 1591 (39.7) & 1541 (41.0) \\
\hline No & $2502(60.3)$ & $2419(60.3)$ & $2215(59.0)$ \\
\hline Smoking (pregnancy) & & $P=0.01$ & $P<0.001$ \\
\hline Yes & $1142(27.5)$ & $1092(27.2)$ & $995(26.5)$ \\
\hline No & $3005(72.3)$ & $2919(72.8)$ & $2762(73.5)$ \\
\hline Child's sex & & $P=0.36$ & $P=0.82$ \\
\hline Boy & $2157(52.0)$ & $2081(51.9)$ & $1952(52.0)$ \\
\hline Girl & $1990(48.0)$ & $1930(48.1)$ & $1805(48.0)$ \\
\hline
\end{tabular}

Survival analysis

The total BF $(n=3738)$ and $\operatorname{EBF}(n=3901)$ median durations were 7.0 months and 1.5 months, respectively. There were no differences in duration of any BF or EBF according GWG categories. In relation with pre-pregnancy BMI the median durations of exclusive and total BF were decrease in underweight and obese groups (Table 2). In smoking mothers, the survival analysis adjusted to maternal and child covariates indicated some effect of mothers' obesity on duration of any BF compared with normal-weight mothers, with a hazard ratio (HR) for weaning of 1.50 (95\% confidence interval $(\mathrm{Cl}) 1.18-1.90)$. The adjusted HR also showed that maternal obesity and overweight were significantly associated with shorter duration of EBF (HR 1.49, 95\% Cl: 1.18-1.87 and HR 1.18, 95\% Cl: 1.02-1.37), respectively. The survival time of any BF (stratified by maternal smoking in pregnancy) and EBF (stratified by parity)over the time for pre-pregnancy BMI categories are shown in Figures 1 and 2.

Proportional hazard regressions showed no effect of GWG categories on duration of any BF: HR $1.02(95 \% \mathrm{Cl} 0.93-1.11)$ and HR 0.99 (95\% Cl 0.91-1.08) for insufficient and excessive GWG, respectively, compared with women with sufficient GWG; or on duration of EBF: HR 1.02 (95\% Cl 0.94-1.12) for insufficient GWG 
and HR 1.07 (95\% Cl 0.97-1.60) for excessive GWG, as compared with women with sufficient GWG.

Table 3 shows the prevalence of BF patterns at 3 months of child's age according to pre-pregnancy BMI and GWG categories. Information on BF patterns was available to 4011 infants: $27.0 \%$ were given EBF; $18.1 \%$, predominant $\mathrm{BF} ; 28.8 \%$, partial $\mathrm{BF}$; and $26.0 \%$ had already been weaned. Mothers with normal prepregnancy BMI had a higher proportion of infants in partial BF (29.9\%) and EBF (28.6\%); the overweight mothers had tendency by EBF $(27.7 \%)$ and partial BF (26.8\%); and more than one-third $(34.6 \%)$ of the infants from obese mothers had already been weaned at the age of 3 months. Remarkably, mothers with underweight BMI had a higher proportion of infants in weaned

Table 2. Median duration of total and exclusive BF according maternal pre-pregnancy BMI and GWG (2004 Cohort Pelotas, Brazil)

\begin{tabular}{lcc}
\hline & Total BF $(\mathrm{N}=3738)$ & Exclusive BF $(\mathrm{N}=3901)$ \\
\hline & Median $(I Q R)$ & Median $(I Q R)$ \\
\hline Total & $7.0(0.5 ; 46.0)$ & $1.5(0.06 ; 6.0)$ \\
& & \\
Pre-pregnancy BMI & & \\
Underweight & $5.0(0.5 ; 36.0)$ & $1.0(0.03 ; 5.0)$ \\
$\quad$ Normal weight & $7.0(0.5 ; 42.0)$ & $1.6(0.06 ; 6.0)$ \\
Overweight & $7.0(0.5 ; 48.0)$ & $1.5(0.03 ; 6.0)$ \\
Obese & $6.0(0.3 ; 48.0)$ & $1.2(0.06 ; 6.0)$ \\
GWG (IOM) & & \\
Insufficient & $6.5(0.5 ; 46.5)$ & $1.5(0.03 ; 6.0)$ \\
Sufficient & $7.0(0.7 ; 44.0)$ & $1.5(0.06 ; 6.0)$ \\
Excessive & $7.0(0.5 ; 48.0)$ & $1.5(0.06 ; 6.0)$ \\
\hline
\end{tabular}

Abbreviations: BF, breastfeeding; BMl, body mass index; GWG, gestational weight gain; IOM, Institute of Medicine; IQR, interquartile range. Excluded the weaned.
(30.4\%) and partial BF (30.4\%) and a lower proportion in predominant (18.2\%) and exclusive BF (21.0\%).

Figure 3 shows the predicted probabilities for each maternal pre-pregnancy BMI and GWG categories, averaging across BF patterns categories. The marginal effects were obtained as discrete differences. Between obese mothers, the average probability of wean before completing 3 months after the delivery was $0.36(95 \% \mathrm{Cl} 0.31-0.41)$ and among normal-weighted mothers the average probability was $0.23(95 \% \mathrm{Cl} 0.21-0.25)$. So, among infants from mothers with normal pre-pregnancy BMI the probability of being weaned at the age of 3 months was in average 13 percentage points lower than among infants from obese mothers. No marginal discrete differences were found using maternal GWG as predictor.

\section{DISCUSSION}

This study found three clear associations: first, infants of obese mothers present an increased probability of weaning at 3 months of age when compared with infants of normal-weight mothers. Second, the observed interaction between maternal smoking and pre-pregnancy BMI highlights the negative effect of obesity on total BF duration in smoking mother's subgroup. And third, the interaction between parity and pre-pregnancy BMI emphasizes a negative effect of obesity on EBF duration in primiparous mother's subgroup. The GWG was not associated with any BF or EBF duration after adjusting for confounding variables, findings supported by some other observational studies. ${ }^{18-20}$

The Pelotas BF median duration in 2004 (7.0 months) is higher compared with 1982 (3.1 months) and 1993 (4.0 months). ${ }^{21}$ However, both EBF (1.5 months) and BF median durations have not achieved the current World Health Organization recommendation during the first 6 and 24 months of life, respectively. ${ }^{22}$

Studies from high-income countries indicate a decrease in BF initiation among obese women, compared with their normalweight counterparts. ${ }^{23}$ In the current study, any difference was a

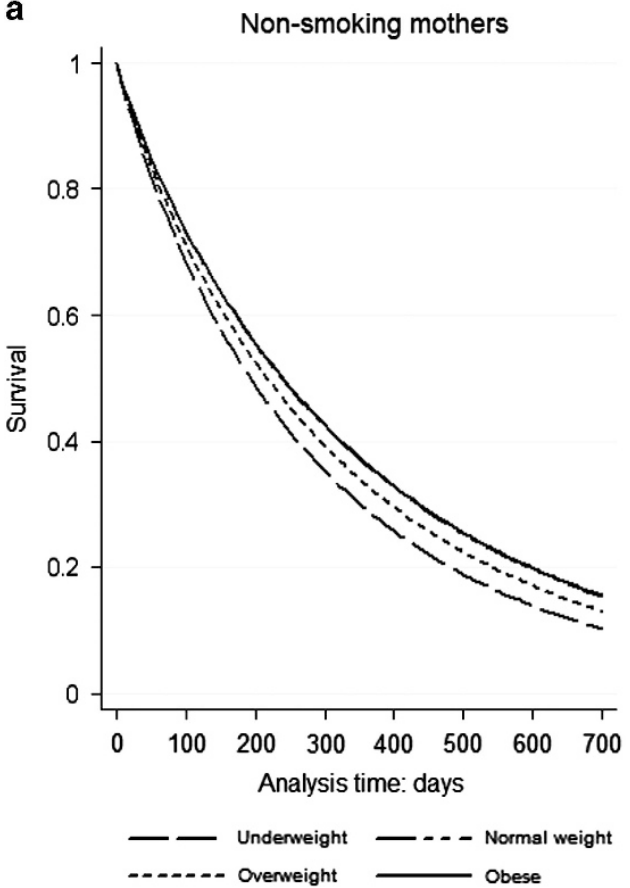

b

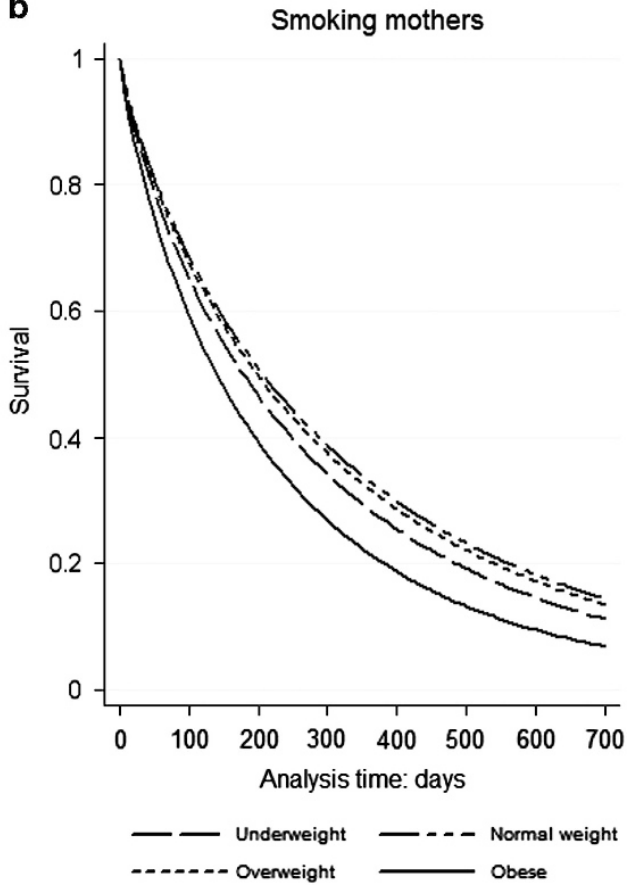

Figure 1. Adjusted survival analyses of total breastfeeding duration as assessed at 24 months post partum by pre-pregnancy BMI category, among (a) non-smoking mothers $(n=2648)$ and (b) smoking mothers $(n=939)$. Analyses controlled for maternal age, education, parity, history of diseases in pregnancy (diabetes and arterial hypertension), alcohol consumption, child's sex, gestational age, birth weight and type of delivery. 
a

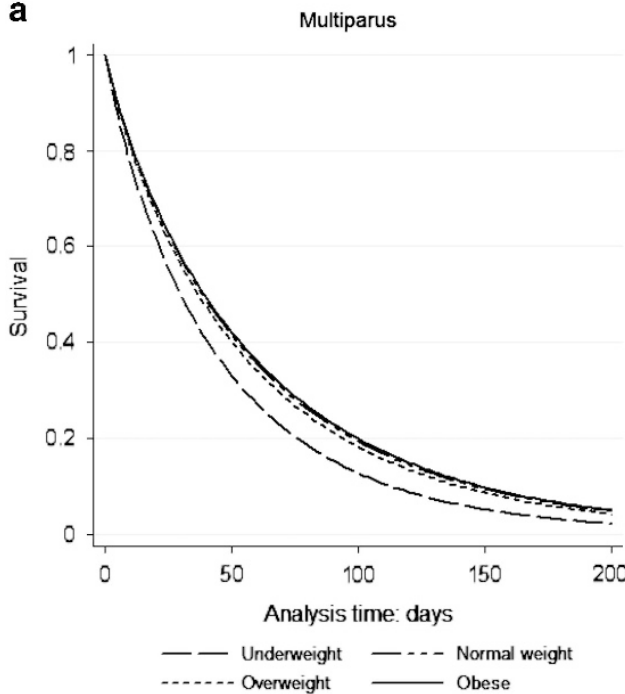

b

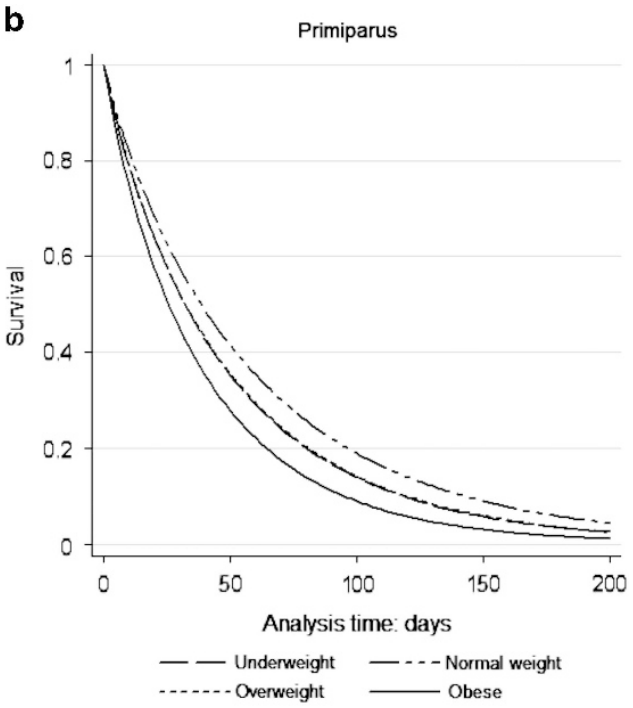

Figure 2. Survival analyses for exclusive breastfeeding until 6 months post partum by pre-pregnancy BMl category, among (a) multiparus $(n=1968)$ and (b) primiparous $(n=1382)$. Analyses controlled for maternal age, education, smoking, history of diseases (diabetes and arterial hypertension), alcohol consumption, child's sex, gestational age, birth weight and type of delivery.

Table 3. BF pattern at 3 months of age according to maternal demographic, socio-economic, reproductive and behavioral characteristics, and to child characteristics at birth (2004 Cohort Pelotas, Brazil)

\begin{tabular}{|c|c|c|c|c|c|c|}
\hline \multirow[t]{2}{*}{ Co-variables } & \multirow[t]{2}{*}{$\mathrm{N}(\%)$} & \multicolumn{4}{|c|}{ Breastfeeding pattern at 3 months of age } & \multirow[t]{2}{*}{ P-value } \\
\hline & & $\begin{array}{l}\text { Weaned } \\
\mathrm{N}(\%)\end{array}$ & $\begin{array}{l}\text { Partial } \\
\mathrm{N}(\%)\end{array}$ & $\begin{array}{c}\text { Predominant } \\
\text { N (\%) }\end{array}$ & $\begin{array}{l}\text { Exclusive } \\
\mathrm{N}(\%)\end{array}$ & \\
\hline Total & 4011 & $1044(26.0)$ & $1157(28.8)$ & $726(18.1)$ & $1084(27.0)$ & \multirow{3}{*}{$<0.001$} \\
\hline \multicolumn{7}{|l|}{ Pre-pregnancy BMI } \\
\hline Overweight & $877(23.3)$ & $222(25.3)$ & $235(26.8)$ & $177(20.2)$ & $243(27.7)$ & \\
\hline Obesity & $413(10.9)$ & $142(34.6)$ & $102(24.7)$ & $64(15.5)$ & $104(25.2)$ & \\
\hline \multicolumn{7}{|l|}{ GWG (IOM) } \\
\hline Insufficient & 1131 (30.4) & $296(26.2)$ & 352 (31.1) & 198 (17.5) & $285(25.2)$ & \multirow[t]{2}{*}{0.07} \\
\hline Sufficient & $1355(36.4)$ & $334(24.7)$ & $386(28.5)$ & $241(17.8)$ & $394(29.1)$ & \\
\hline
\end{tabular}

found between pre-pregnancy BMI categories. In the majority of observational studies, the obese women are at increased risk of a shortened duration of any BF and of discontinuing BF earlier compared with normal-weight women. ${ }^{24}$ However, none of the previous studies explored effect modification in multivariable adjusted analysis but not all the studies included the socioeconomic status as a potential confounding factor in their statistical analyses.

In smoking mothers, the effect of obesity on discontinuation of any BF compared with normal-weight mothers could be due to a lower number of antenatal care visits attended by smoking mothers and consequently, less likely to breastfeed. ${ }^{25}$ Smoking obese mothers may be less health conscious. Horta et al. ${ }^{25}$ reported that family income, schooling and number of antenatal care visits were inversely associated with the prevalence of maternal smoking. In addition, there is biological plausibility to the causal inference that maternal smoking increases the risk of early weaning: nicotine increases dopamine secretion in the hypothalamus, thereby reducing prolactin levels. ${ }^{26}$
Underweight multiparous mothers and obese primiparous mothers had higher probability to discontinuing EBF before 3 months after delivery. Lactation can be considered a reproductive stress to women, thus promoting weight gain in chronically or acute undernourished women in detriment of the infant growth; women who are undernourished at the time of conception are unlikely with improve their nutritional status during pregnancy. ${ }^{27}$

Further, clinical and behavioral factors could differentiate the primiparous mothers: obesity is associated with obstetrical complications in primiparous obese women, who are to be considered risky patients at their arrival in the labor ward, and specific obstetrical management must be planned to improve maternal and neonatal outcomes. ${ }^{28}$ The primiparous intention to EBF is higher than the rate of EBF after birth. Women who have breastfed previously have significantly different BF experiences than primiparous women. ${ }^{28}$

Other series of hypotheses trying to explain possible reasons why overweight/obese women are less likely to breastfeed have been proposed in the literature: (a) delayed lactogenesis and lower prolactin response to suckling in obese women; ${ }^{29}$ 

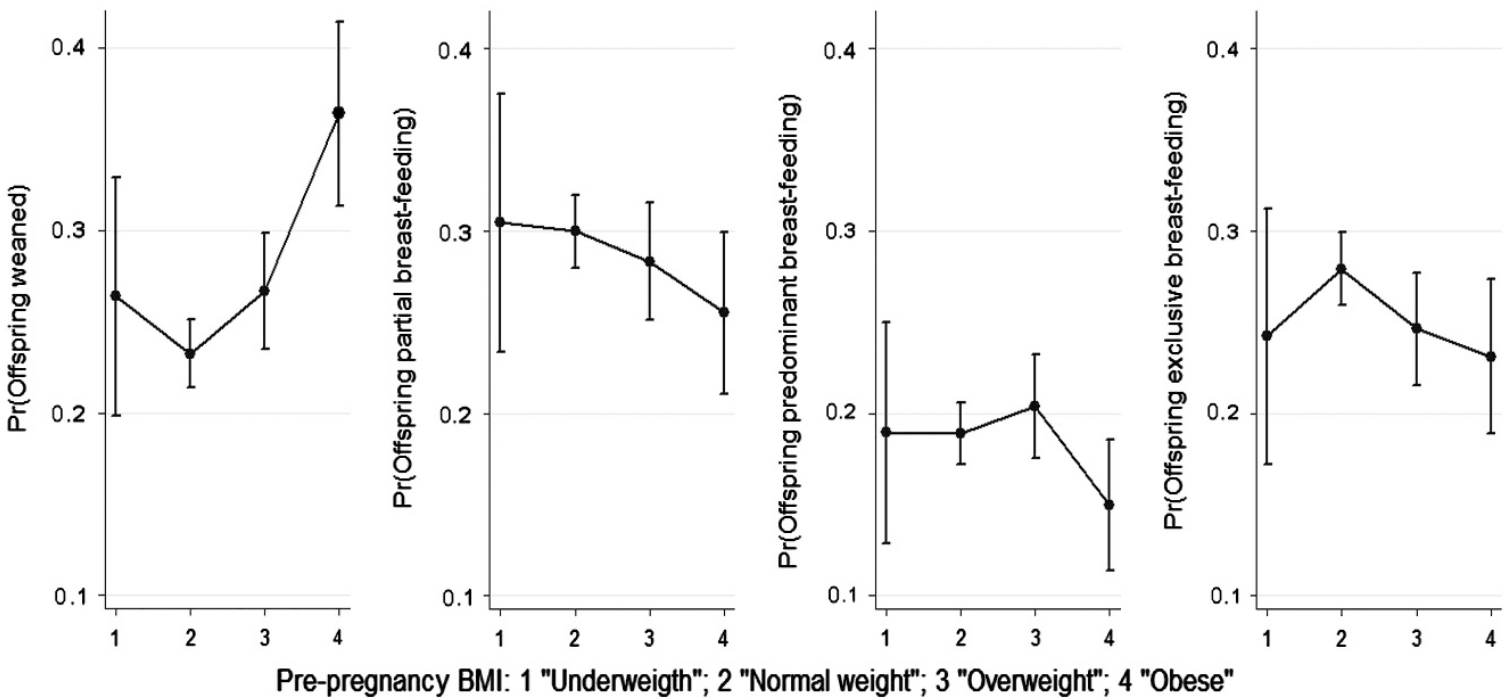

b Ajusted predictions of maternal gestational gain weight categories with $95 \% \mathrm{Cls}$
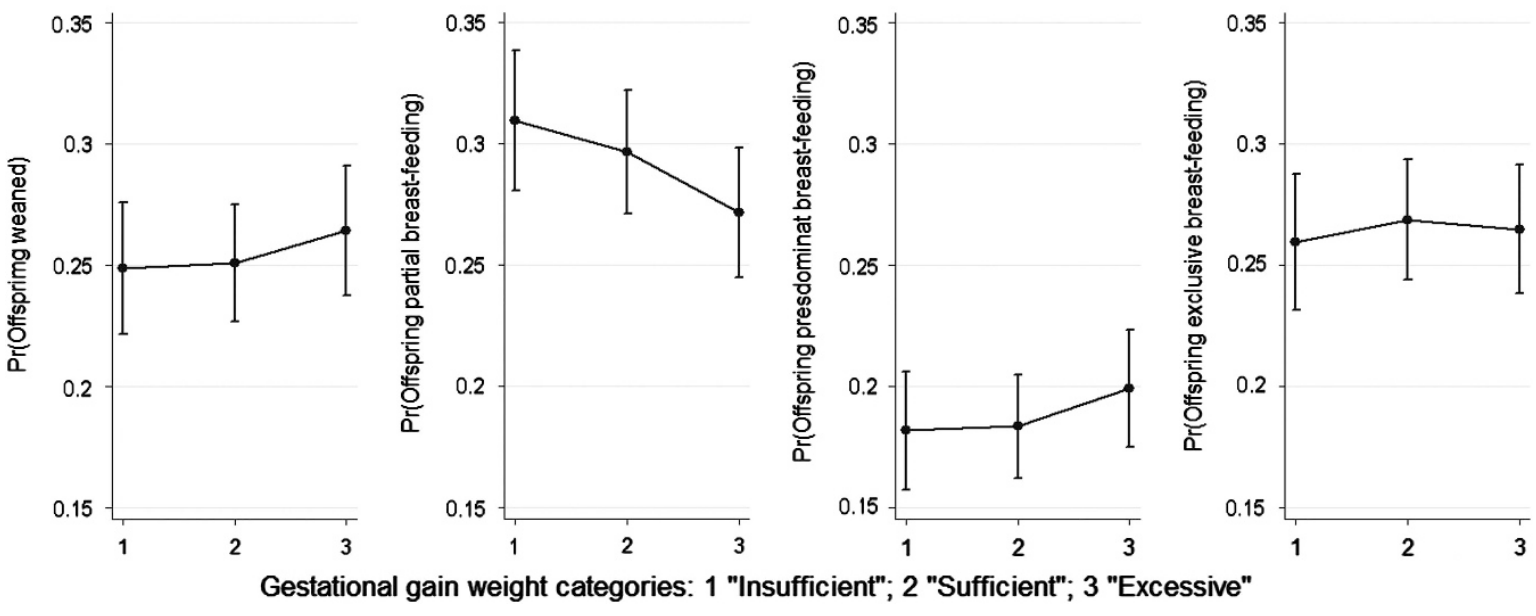

Figure 3. Predicted probabilities of breastfeeding (BF) patterns at 3 months of age according to: (a) maternal pre-pregnancy body mass index (BMI) categories (analyses controlled for family income, maternal age, education, parity, history of diabetes and arterial hypertension, alcohol consumption, smoking, GWG, child's sex, gestational age, birth weight and type of delivery); (b) Gestational weight gain (GWG) in IOM categories (analyses controlled for family income, maternal age, education, parity, pre-pregnancy BMI, history of diabetes and arterial hypertension, alcohol consumption, smoking, child's sex, gestational age, birth weight and type of delivery).

(b) adipose tissue would act as a reservoir for steroid hormones then leading to higher progesterone levels in obese women than normal-weight; ${ }^{30}$ (c) large breast in obese women have been associated with BF practical/mechanical difficulties; ${ }^{31}$ (d) mother medical conditions (obstetric complications, cesarean section, metabolic diseases, diabetes and polycystic ovary syndrome) in overweight and obese women may lead to delayed lactogenesis; ${ }^{32}$ (e) psychological factors in obese women (body image dissatisfaction, post-partum depression, lack of confidence about sufficient milk supply) ${ }^{33}$ can turn them less likely to continue BF than normal-weight or non-depressed women; and ( $f$ ) socio-cultural environment, lower socio-economic status, smoking mothers have lower intention to breastfeed. ${ }^{33,34}$

The strength of this study was the large cohort, the populationbased recruitment, the nature of data collection and the high percentage of children followed-up at age $3(95.7 \%), 12$ (94.3\%) and $24(92.0 \%)$ months. ${ }^{10}$ More than $90 \%$ of children from all the categories of the baseline characteristics were available for the current analyses. However, the accuracy of the self-reported prepregnancy weight as gathered from some of the mothers is a limitation; a degree of measurement error can be expected. The adult weight is generally underestimated by self-reported measures, especially in overweight and obese groups and overestimated in underweight groups. ${ }^{35}$ Even though, the high correlation between weight measurement and self-reported weight would allow for adequate BMI category classification. ${ }^{36}$

\section{CONCLUSION}

In summary, after allowing for confounders, this study found that maternal pre-pregnancy overweight and obesity are negatively associated with duration of any BF and EBF. BF is indispensable for children's health. The protective effect of BF is against all-cause of mortality in infants. Children who are not breastfed have repeated infections and hospitalizations. ${ }^{37}$ It is possible that the higher proportion of underweight and obese mothers that were no 
longer $\mathrm{BF}$ at 3 months of age is due to biological reasons and guidance or information on BF will not work, as women are simply not able to follow the recommended guidelines. This study identified underweight, overweight and obese women population as risk groups to early weaning and uncovered the necessity to focalize a supplementary guidance about BF benefits to mother and infant health during prenatal and postnatal care. Moreover, it is necessary to create heath strategies of promotion, prevention and support to follow the recommended nutritional status according to BMI classification in reproductive age women population.

\section{CONFLICT OF INTEREST}

The authors declare no conflict of interest.

\section{ACKNOWLEDGEMENTS}

This article is based on data from the study 'Pelotas Birth Cohort, 2004' conducted by Postgraduate Program in Epidemiology at Universidade Federal de Pelotas, with the collaboration of the Brazilian Public Health Association (ABRASCO). From 2009 to 2013, the Wellcome Trust supported the 2004 birth cohort study. The World Health Organization, National Support Program for Centers of Excellence (PRONEX), Brazilian National Research Council (CNPq), Brazilian Ministry of Health and Children's Pastorate supported previous phases of the study. IS Santos and A Matijasevich receive research support from the National Council for Scientific and Technological Development (CNPq), Brazil.

\section{REFERENCES}

1 Bhurosy T, Jeewon R. Overweight and obesity epidemic in developing countries: a problem with diet, physical activity, or socioeconomic status? ScientificWorldJournal 2014; 2014: 964236.

2 Webber L, Kilpi F, Marsh T, Rtveladze K, Brown M, McPherson K. High rates of obesity and non-communicable diseases predicted across Latin America. PLoS One 2012; 7: 39589.

3 Cedergren MI. Maternal morbid obesity and the risk of adverse pregnancy outcome. Obstet Gynecol 2004; 103: 219-224.

4 Hilson JA, Rasmussen KM, Kjolhede CL. High prepregnant body mass index is associated with poor lactation outcomes among white, rural women independent of psychosocial and demographic correlates. $J$ Hum Lact 2004; 20: 18-29.

5 Baker JL, Michaelsen KF, Sorensen TI, Rasmussen KM. High prepregnant body mass index is associated with early termination of full and any breastfeeding in Danish women. Am J Clin Nutr 2007; 86: 404-411.

6 Baker JL, Michaelsen KF, Rasmussen KM, Sorensen TI. Maternal prepregnant body mass index, duration of breastfeeding, and timing of complementary food introduction are associated with infant weight gain. Am J Clin Nutr 2004; 80: 1579-1588.

7 Begum F, Colman I, McCargar LJ, Bell RC. Gestational weight gain and early postpartum weight retention in a prospective cohort of Alberta women. J Obstet Gynaecol Can 2012; 34: 637-647.

8 Esteves TM, Daumas RP, Oliveira MI, Andrade CA, Leite IC. Factors associated to breastfeeding in the first hour of life: systematic review. Rev Saude Publica 2014; 48: 697-708.

9 Meedya S, Fahy K, Kable A. Factors that positively influence breastfeeding duration to 6 months: a literature review. Women Birth 2010; 23: 135-145.

10 Santos IS, Barros AJ, Matijasevich A, Domingues MR, Barros FC, Victora CG. Cohort profile: the 2004 Pelotas (Brazil) birth cohort study. Int J Epidemiol 2011; 40: 1461-1468.

11 Instititute of Medicine. Weight Gain During Pregnancy: Reexamining the Guidelines. In: KM Rasmussen and AL Yaktine (eds). Washington, DC, USA, 2009.

12 Committee to Reexamine IOM Pregnancy Weight Guidelines. Food and Nutrition Board, Board on Children, Youth and Families, Institute of Medicine, National Research Council: Weight Gain During Pregnancy: Reexamining the Guidelines. The National Academies Press: Washington, DC, USA, 2009.

13 Santos IS, Mota DM, Matijasevich A, Barros AJ, Barros FC. Bed-sharing at 3 months and breast-feeding at 1 year in southern Brazil. J Pediatr 2009; 155: 505-509.
14 WHO. The World Health Organization's infant-feeding recommendation An evaluation of infant growth: the use and interpretation of anthropometry in infants. WHO Working Group on Infant Growth. Bull World Health Organ 1995; 73: 165-174.

15 Martin JA, Hamilton BE, Sutton PD, Ventura SJ, Menacker F, Munson ML. Births: final data for 2003. Natl Vital Stat Rep 2005; 54: 1-116.

16 Fenton TR. A new growth chart for preterm babies: Babson and Benda's chart updated with recent data and a new format. BMC Pediatr 2003; 3: 13.

17 Dubowitz LM, Dubowitz V, Goldberg C. Clinical assessment of gestational age in the newborn infant. J Pediatr 1970; 77: 1-10.

18 Bartok CJ, Schaefer EW, Beiler JS, Paul IM. Role of body mass index and gestational weight gain in breastfeeding outcomes. Breastfeed Med 2012; 7: 448-456.

19 Olson CM, Strawderman MS, Hinton PS, Pearson TA. Gestational weight gain and postpartum behaviors associated with weight change from early pregnancy to $1 \mathrm{y}$ postpartum. Int J Obes Relat Metab Disord 2003; 27: 117-127.

20 Petrucci Gigante D, Victora CG, Barros FC. Maternal nutrition and duration of breastfeeding in a birth cohort in Pelotas, Brazil. Rev Saude Publica 2000; 34: 259-265.

21 Victora CG, Matijasevich A, Santos IS, Barros AJ, Horta BL, Barros FC. Breastfeeding and feeding patterns in three birth cohorts in Southern Brazil: trends and differentials. Cad Saude Publica 2008; 24: S409-S416.

22 World Health Organization. Indicators for assessing infant and young child feeding practices: conclusions of a consensus meeting held 6-8 November 2007 in Washington, DC, USA. 2011.

23 Turcksin R, Bel S, Galjaard S, Devlieger R. Maternal obesity and breastfeeding intention, initiation, intensity and duration: a systematic review. Matern Child Nutr 2014; 10: 166-183.

24 Amir LH, Donath S. A systematic review of maternal obesity and breastfeeding intention, initiation and duration. BMC Pregnancy Childbirth 2007; 7: 9.

25 Horta LB, Victora GC, Barros FC, Santos SI, Menezes AM. Tabagismo em gestantes de área urbana da região Sul do Brasil: 1982 e 1993. Revista de Saude Publica 1997; 31: 247-253.

26 Baron JA, Bulbrook R, Wang D, Kwa H. Cigarette smoking and prolactin in women. Br Med J 1986; 293: 482-483.

27 Kusin JA, Kardjati S, Renqvist UH. Chronic undernutrition in pregnancy and lactation. Proc Nutr Soc 1993; 52: 19-28.

28 Briese V, Voigt M, Wisser J, Borchardt U, Straube S. Risks of pregnancy and birth in obese primiparous women: an analysis of German perinatal statistics. Arch Gynecol Obstet 2011; 283: 249-253.

29 Rasmussen KM, Kjolhede CL. Prepregnant overweight and obesity diminish the prolactin response to suckling in the first week postpartum. Pediatrics 2004; 113 : 465-471.

30 Norman RJ, Clark AM. Obesity and reproductive disorders: a review. Reprod Fertil Dev 1998; 10: 55-63.

31 Katz KA, Nilsson I, Rasmussen KM. Danish health care providers' perception of breastfeeding difficulty experienced by women who are obese, have large breasts, or both. J Hum Lact 2010; 26: 138-147.

32 Yu CK, Teoh TG, Robinson S. Obesity in pregnancy. J Br Obstet Gynaecol 2006; 113 : 1117-1125.

33 Keely A, Lawton J, Swanson V, Denison FC. Barriers to breast-feeding in obese women: a qualitative exploration. Midwifery 2015; 31: 532-539.

34 Ludvigsson JF, Ludvigsson J. Socio-economic determinants, maternal smoking and coffee consumption, and exclusive breastfeeding in 10205 children. Acta Paediatr 2005; 94: 1310-1319.

35 Yu SM, Nagey DA. Validity of self-reported pregravid weight. Ann Epidemiol 1992; 2: 715-721.

36 Holland E, Moore Simas TA, Doyle Curiale DK, Liao X, Waring ME. Self-reported pre-pregnancy weight versus weight measured at first prenatal visit: effects on categorization of pre-pregnancy body mass index. Matern Child Health J 2013; 17: 1872-1878.

37 Lamberti LM, Fischer Walker CL, Noiman A, Victora C, Black RE. Breastfeeding and the risk for diarrhea morbidity and mortality. BMC Public Health 2011; 11: S15.

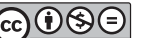

This work is licensed under a Creative Commons AttributionNonCommercial-NoDerivs 4.0 International License. The images or other third party material in this article are included in the article's Creative Commons license, unless indicated otherwise in the credit line; if the material is not included under the Creative Commons license, users will need to obtain permission from the license holder to reproduce the material. To view a copy of this license, visit http:// creativecommons.org/licenses/by-nc-nd/4.0/ 